\title{
Dual-switchable surfaces between hydrophobic and superhydrophobic fabricated by the combination of click chemistry and RAFT
}

\author{
M. S. Han, X. Y. Zhang, L. Li, C. Peng, L. Bao, E. C. Ou, Y. Q. Xiong, W. J. Xu* \\ Institute of Polymer Science and Technology, College of Chemistry and Chemical Engineering, Hunan University, 410082 \\ Changsha, P.R. China
}

Received 1 January 2014; accepted in revised form 1 April 2014

\begin{abstract}
A dual-switchable surface between hydrophobic and superhydrophobic has been fabricated successfully by combining reversible addition-fragmentation chain transfer polymerization (RAFT) polymeric technology and thiol-NCO click chemistry. Well-defined block copolymer, poly(7-(6-(acryloyloxy) hexyloxy) coumarin)- $b$-poly(N-Isopropylacryl amide), was synthesized by RAFT, and then the block copolymer was grafted onto the surface of $\mathrm{SiO}_{2}$ modified by toluene disocynate (TDI) via thiol-NCO click chemistry. The results of nuclear magnetic resonance (NMR) and Fourier Transform Infrared (FTIR) spectroscopies confirmed that the block copolymer (Number average molecular weight $\left(M_{\mathrm{n}}\right)=9400$, polydispersity index $(\mathrm{PDI})=1.22$ ) has been synthesized successfully. The static contact angle $(\mathrm{CA})$ of the surface prepared by $\mathrm{SiO}_{2} / \mathrm{P}$ (7-6-AC)- $b$-PNIPAAm switches from $98 \pm 2$ to $137 \pm 2^{\circ}$ by adjusting the temperature. Furthermore, the contact angle can also oscillate between $137 \pm 2$ and $157 \pm 2^{\circ}$ on the irradiation of UV light at 365 and $254 \mathrm{~nm}$, respectively. The dual-switchable surfaces exhibit high stability between hydrophilicity and superhydrophobicity. Therefore, the method provides a new method to fabricate the dual-stimuli-responsive surface with tunable wettability, reversible switching, and also be easily extended to other dual-responsive surfaces. This ability to control the wettability by the adjustment of the temperature and UV light has applications in a broad range of fields.
\end{abstract}

Keywords: polymer composites, superhydrophobic surface, photo-sensitive, thermal-sensitive, click chemistry

\section{Introduction}

The wetting properties of superhydrophobic surfaces have received worldwide and tremendous attention [1] since the dual hierarchical structure of the lotus leaf was discovered [2]. Lotus-Leaf-like superhydrophobic surfaces, exhibit an amazing property for not only being wetted by water leading to a self-cleaning effect [3], but also for their great advantages in applications. In recent years, superhydrophobic surfaces are widely used in the human body implant materials [4], microfluidic tools [5], Calix azacrown [6], tunable optical lenses [7], labon-chip systems [8]. The wettability of the surface is influenced by its chemical composition and morphology [9], because chemical composition determines the surface free energy, and a lower surface energy leads to higher hydrophobicity. Additionally, the hierarchical structure (micro roughness covered with nano roughness) was not only necessary for a high contact angle (CA) but essential for the stability of the water-solid and water-air interfaces [10] (the composite interface). For example, Wang et al. [11] prepared cauliflower-like silica nanospheres with tunable wettability through regulating chemical compositions. The chemical etching method [12] used to prepare the superhydrophobic $\mathrm{CuO}$

\footnotetext{
${ }^{*}$ Corresponding author, e-mail: weijianxu59@gmail.com

(C) BME-PT
} 
surfaces with tunable adhesion by controlling the etching time to control the morphology. However, these reports mainly focused on realizing controllable wettability by different means, rather than the reversibility and did not consider the transition of the reversible.

Functional surfaces with controlled wetting properties responsive to external stimuli become more attractive for both the scientific interest and the practical application due to the wide range of their potential applications. A variety of approaches including appropriate external stimuli [13], and exchange of counterions [14] can dynamically trigger the reversible wettability conversion. The external stimuli-responsive superhydrophobic materials have been intensively studied, and many positive results have also been obtained [15]. External stimuli, such as light illumination [16], temperature [17], curvature driven [18], ion pairs driven [19], $\mathrm{pH}$ [20], can change the surface conformation or morphology of stimuli-sensitive materials, thus resulting in the change of wettability. However, most of these wetting surfaces are responsive to only single stimulus, such as temperature, optical or electric field, and this may be the limitation in many important practical applications with complex environments, such as biological devices, which often need the surface can respond to more than one stimulus simultaneously [21]. It is, therefore, desirable to design dualor multiresponsive surfaces to meet with the needs of double or multi-stimulation in complex environments.

Multiple functional and responsive surfaces with special wettability and reversible properties, especially thermal-sensitive and photo-sensitive surfaces, have an extensive range of application in many important fields [22-24]. Recently, several thermally, $\mathrm{pH}$, or optically responsive smart interfacial materials that can switch between superhydrophilicity and superhydrophobicity or hydrophobicity and superhydrophobicity have been reported [25-27]. For the responsive superhydrophobic surfaces, it is necessary to graft some responsive groups, onto the surface of inorganic materials or organic compounds for example, a temperature-responsive polymer poly (N-isopropyl acrylamide (PNIPAAm) [28], reversible $\mathrm{pH}$-responsive group [29], photosensitive materials [30], such as spiropyram [31], coumarin [32] and azobenzene $[33,34]$. Therefore, grafting functional group or polymer with a responsive group onto the inorganic sphere surface to construct multi-responsive superhydrophobic materials is a feasible method, and the most effective method to achieve the goal is the click chemistry [35] which can fabricate the core-shell structure. Additionally, it is convenient to tune the surface roughness by controlling click reaction cycles $[35,36]$ to obtain hierarchical structures with different sizes of $\mathrm{SiO}_{2}$. Coumarin and its derivatives are one of the most common used to prepare for photo-sensitive materials, such as the superhydrophobic materials [32], which are potentially applied in biological and medical fields [3739]. Reversible addition-fragmentation chain transfer polymerization (RAFT) is an effective method to synthesize living/controlled polymer and now have been applied in polymerizing PVAc [40], PHEMA [41], P4VP [42], PNIPAAm [43], PS [44] etc. The high degree of compatibility with a wide range of functional monomers and good tolerance of water and oxygen in the systems make RAFT technique has been widely used in the synthesis of functional polymers. For example, coumarin and its derivatives have been successfully grafted onto the chain of polymer by living free radical polymerization $[45,46]$.

In this work, we report a method for the fabrication of photo- and thermal-sensitive superhydrophobic surface by the combination of RAFT and click chemistry, resulting in that the block polymers are grafted onto the surface of silica nanosphere. The strategies in our work not only improve the grafting rate between the organic group and inorganic materials by click chemistry (thiol-NCO), but also increase the stability of the superhydrophobic materials. Moreover, the copolymers containing coumarin and Nisopmpylacrylamide group can be easily synthesized by RAFT polymeric technology, and a superhydrophobic surface can be designed and constructed by using the multiple responsive block polymers which synthesized by RAFT polymeric technology. To the best of our knowledge, it is the first time to fabricate photo-sensitive and thermal-sensitive superhydrophobic surfaces by the combination of 'click' chemistry and RAFT polymeric technology, and graft the block polymer onto the silica surface. Therefore, it would provide a new pathway to fabricate multiple responsive superhydrophobic surfaces, and other responsive superhydrophobic surfaces can be designed and prepared by this method. 


\section{Experimental section 2.1. Materials}

All the other chemicals were analytical grade and used as received without further purification. 7Hydroxy coumarin (7-AC) was received from Ziyan Chemical Co. Ltd (Lianyungang, China). 1,6-dibromohexane, silica nanoparticle and N-Isopropylacrylamide (NIPAAm recrystallized twice from benzene/ hexane) was purchased from Aladdin Co. Ltd. (Shanghai, China). 2-Cyanoprop-2-yl-dithiobenzoate (CPDB), N, N-dimethyl-formamide (DMF), petroleum ether and ethyl acetate were purchased from Sinopharm Chemical Reagent Co. Ltd (Shanghai, China). Carbonic acid, ethanol, acrylic acid, potassium hydroxide, dibutyltin dilaurate (DBTDL), toluene di-isocyanate (TDI) and azodiisobutyronitrile (AIBN) were commercially available from Tianjin Damao Chemical Reagent Company (Tianjin, China), respectively.

\subsection{Synthesis of 7-(6-bromohexyloxy) coumarin}

The mixture of 7-hydroxy coumarin $(10.0 \mathrm{~g}$, $62 \mathrm{mmol}$ ) and excess 1,6-dibromohexane (45 g, $186 \mathrm{mmol})$ were dissolved in acetone $(200 \mathrm{~mL})$, then anhydrous $\mathrm{K}_{2} \mathrm{CO}_{3}(17.4 \mathrm{~g}, 124 \mathrm{mmol})$ was added into the flask. The resulted suspension was heated to reflux for $24 \mathrm{~h}$. The precipitate was filtered off and extracted with acetone $(3 \times 100 \mathrm{~mL})$. After the solvent was removed in reduced pressure, water was added, and used $\mathrm{CH}_{2} \mathrm{Cl}_{2}(3 \times 200 \mathrm{~mL})$ to extract the residue. The extract was dried with anhydrous $\mathrm{MgSO}_{4}$, filtered, and evaporated under reduced pressure. The product was then purified by means of column chromatography on silica oxide with mixed petroleum ether and ethyl acetate $(5: 1, \mathrm{v} / \mathrm{v})$ as eluent, and resulted in a white solid after dried in vacuum drying oven $(14.8 \mathrm{~g}, 74.3 \%)$. The synthesis route of 7(6-bromohexyloxy) coumarin (7-6-BC) is shown in Figure 1a.

${ }^{1} \mathrm{H} \mathrm{NMR}\left(\mathrm{CDCl}_{3}\right): 7.65(\mathrm{~d}, 1 \mathrm{H}), 7.38(\mathrm{~d}, 1 \mathrm{H}), 6.82(\mathrm{~d}$, $1 \mathrm{H}), 6.80(\mathrm{~d}, 1 \mathrm{H}), 4.02(\mathrm{t}, 2 \mathrm{H}), 3.43(\mathrm{t}, 2 \mathrm{H}), 1.90(\mathrm{~m}$, $4 \mathrm{H}), 1.50(\mathrm{~m}, 4 \mathrm{H})$.

\subsection{Synthesis of 7-(6-(acryloyloxy) hexyloxy) coumarin}

7-(6-bromohexyloxy) coumarin $(5.8 \mathrm{~g}, 18 \mathrm{mmol})$ and excess potassium acrylate $(30 \mathrm{~g}, 27 \mathrm{mmol})$ were dissolved in ethanol $(150 \mathrm{~mL})$. Hydroquinone $(0.02 \mathrm{~g}$,
$1.8 \mathrm{mmol}$ ) was added. The solution was heated to reflux for $24 \mathrm{~h}$. The precipitate was filtered off and extracted with ethanol $(3 \times 50 \mathrm{~mL})$. After the solvent was removed in reduced pressure, water was added, and the residue was extracted with $\mathrm{CH}_{2} \mathrm{Cl}_{2}$ $(3 \times 100 \mathrm{~mL})$. The residue was then purified by means of column chromatography on silica oxide with mixed petroleum ether and ethyl acetate $(3: 1, v / v)$ as an eluent and resulted in a white solid after dried in vacuum drying oven $(4.6 \mathrm{~g}, 81.65 \%)$. The synthesis process of 7-(6-(acryloyloxy) hexyloxy) coumarin (7-6-AC) is presented in Figure $1 \mathrm{~b}$.

${ }^{1} \mathrm{H} \mathrm{NMR}\left(\mathrm{CDCl}_{3}\right): 7.65(\mathrm{~d}, 1 \mathrm{H}), 7.37(\mathrm{~d}, 1 \mathrm{H}), 6.80(\mathrm{~m}$, $2 \mathrm{H}), 6.41(\mathrm{~d}, 1 \mathrm{H}), 6.26(\mathrm{~d}, 1 \mathrm{H}), 6.18(\mathrm{~m}, 1 \mathrm{H}), 5.82(\mathrm{t}$, $1 \mathrm{H}), 4.20(\mathrm{t}, 2 \mathrm{H}), 4.03(\mathrm{t}, 2 \mathrm{H}), 1.83(\mathrm{~m}, 2 \mathrm{H}), 1.65(\mathrm{~m}$, $2 \mathrm{H}), 1.5(\mathrm{~m}, 4 \mathrm{H})$.

\subsection{Polymerization of 7-(6-(acryloyloxy) hexyloxy) coumarin by RAFT}

A dry ampoule was filled with 7-(6-(acryloyloxy) hexyloxy) coumarin $(0.5 \mathrm{~g}, 1.58 \mathrm{mmol})$, AIBN $(1.3 \mathrm{mg}, \quad 0.0079 \mathrm{mmol}), \quad \mathrm{CPDB} \quad(8.75 \mathrm{mg}$, $0.0395 \mathrm{mmol}$ ), and $\mathrm{N}, \mathrm{N}$-dimethylformamide (DMF) $(1.5 \mathrm{~mL})$. The Schlenk line was used to keep the ampoule vacuum and filled with nitrogen. Then, the ampoule was placed in an oil bath at the desired temperature to polymerize. At timed intervals, the ampoule was immersed into icy water and then opened. The suspension liquid in the ampoule was dissolved in $2 \mathrm{~mL}$ of tetrahydrofuran (THF) and precipitated into a $200 \mathrm{~mL}$ of methanol. The polymer was obtained by centrifuge at the speed of $15000 \mathrm{rpm}$ and dried at room temperature. The synthesis process of poly7-(6-(acryloyloxy) hexyloxy) coumarin $(\mathrm{P}(7-6-\mathrm{AC}))$ is presented in Figure 1c.

\subsection{Synthesis of $\mathbf{P ( 7 - 6 - A C ) - b - P N I P A A m ~}$}

P7-6-AC (0.1 mmol, $\left.M_{\mathrm{n}}=8300\right)$, AIBN (5.47 mg, $0.033 \mathrm{mmol})$, NIPAAm $(1.13 \mathrm{~g}, 10 \mathrm{mmol})$ were placed in an ampoule (The volume fraction of block copolymer was 30:10), the schlenk line was used to keep the ampoule vacuum and fill with nitrogen, and the process must be repeated at least 3 times or more. Then DMF $(1.5 \mathrm{~mL})$ was added into the ampoule by syringe. The ampoule was placed in an oil bath at the desired temperature. At timed intervals, the suspension liquid in the ampoule was poured into $200 \mathrm{~mL}$ of methanol. The polymer was obtained by the centrifuge at the speed of $15000 \mathrm{rpm}$ and dried 
at room temperature. The scheme and structure for the synthesis of $\mathrm{P}(7-6-\mathrm{AC})-b$-PNIPAAm are described in Figure 1d.

\subsection{Reduction of the end group of P(7-6-AC)-b-PNIPAAm}

The P(7-6-AC)- $b$-PNIPAAm $\left(0.5 \mathrm{~g}, M_{\mathrm{n}}=9400\right)$ was dissolved in THF $(10 \mathrm{~mL})$, then the NaBH4 (114 $\mathrm{mg}, 3 \mathrm{mmol}$ ) was added into the solution by three times very slowly, stirring for 30 min under ice salt bath, and the exhaust system must be kept unobstructed. At last, the icy water was used to quench the activity of $\mathrm{NaBH}_{4}$. The solvent was extracted by $\mathrm{CH}_{2} \mathrm{Cl}_{2}(3 \times 50 \mathrm{~mL})$. Finally, $\mathrm{CH}_{2} \mathrm{Cl}_{2}$ was eliminated by rotating distillation, and solid samples were dried in vacuum at $35^{\circ} \mathrm{C}$ overnight. The synthetic route is shown in Figure 1e.

\subsection{Decoration of silica with toluene diisocyanate}

Silica nanosphere $(14 \mathrm{~nm})$ should be activated in a vacuum drying oven at $110^{\circ} \mathrm{C}$ overnight, then the silica $(0.4 \mathrm{~g})$ was dispersed evenly in ethyl acetate $(120 \mathrm{~mL})$ by ultrasonic cleaner, then DBTDL $(0.5 \mathrm{~mL})$ and TDI $(2 \mathrm{~mL})$ were appended in the reaction system, the flask was placed into an oil bath and heated to $60^{\circ} \mathrm{C}$ for $6 \mathrm{~h}$ under the nitrogen atmos- phere. The final product was separated at the speed of $4000 \mathrm{rpm}$ in centrifuge. Then the products were dried overnight at $60^{\circ} \mathrm{C}$. Schematic representation of the modified silica nanosphere with TDI is given in Figure 2a.

\subsection{The grafting of $P(7-6-A C)-b$-PNIPAAm onto the surface of $\mathrm{SiO}_{2}$}

The reduced P(7-6-AC)- $b$-PNIPAAm $(0.5 \mathrm{~g})$ and silica modified with TDI $(0.1 \mathrm{~g})$ were dissolved in THF $(50 \mathrm{~mL})$. DBTDL $(0.25 \mathrm{mg})$ as catalyst was added. The solution was heated to $40^{\circ} \mathrm{C}$ for $2 \mathrm{~h}$ under the nitrogen atmosphere. The $\mathrm{SiO}_{2} / \mathrm{P}(7-6-$ AC)- $b$-PNIPAAm was obtained after being centrifuged and dried. Schematic representation of the modified silica nanosphere with TDI is given in Figure 2b.

\subsection{Preparation of the film to measure the contact angles}

Silicon wafers were ultrasonically cleaned in water and acetone for $10 \mathrm{~min}$, respectively. Then the asprepared $\mathrm{SiO}_{2} / \mathrm{P}$ (7-6-AC)- $b$-PNIPAAm dispersions were coated on the silicon wafer, and dried at room temperature for $24 \mathrm{~h}$. The static water contact angles were measured with deionized water $(4 \mu \mathrm{L})$ on a contact angle goniometer (JC2001) instrument at room

(a)

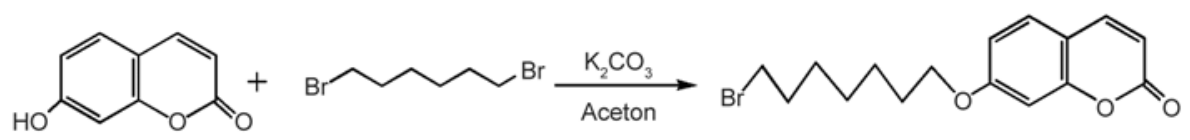

(b)
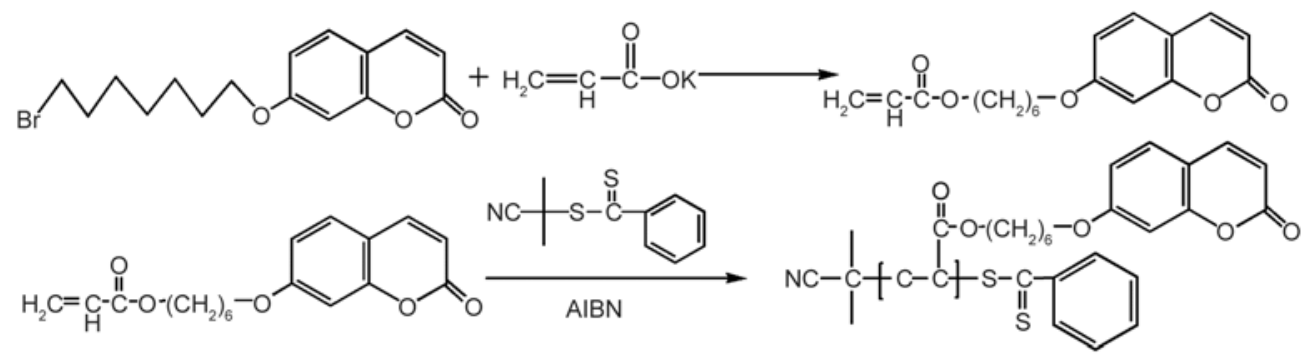

(c)

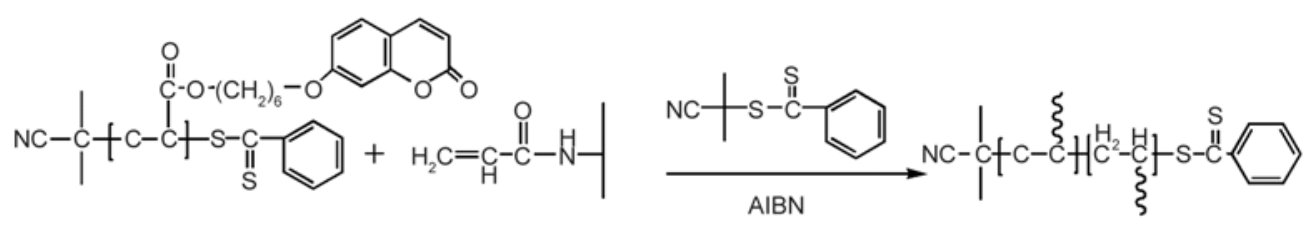

(e)

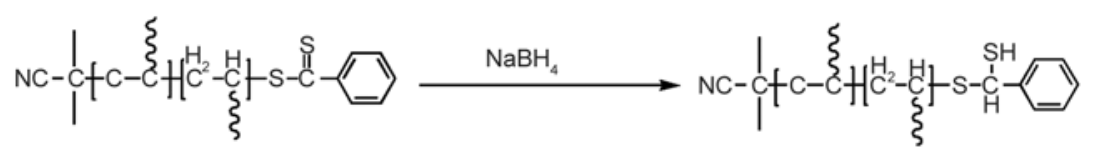

Figure 1. The scheme and structure for the synthesis of (a) 7-(6-bromohexyloxy) coumarin, (b) 7-(6-(acryloyloxy) hexyloxy) coumarin, (c) poly 7-(6-(acryloyloxy) hexyloxy) coumarin, (d) P(7-6-AC)-b-PNIPAAm, and (e) the reduction of the end group of P(7-6-AC)-b-PNIPAAm 
a)
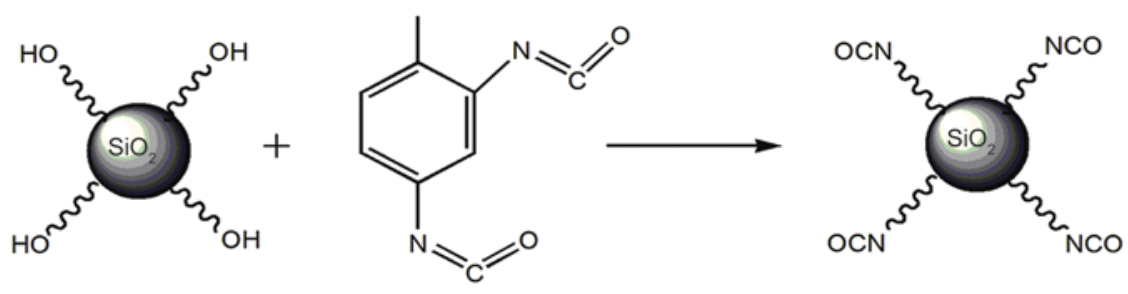

(b)

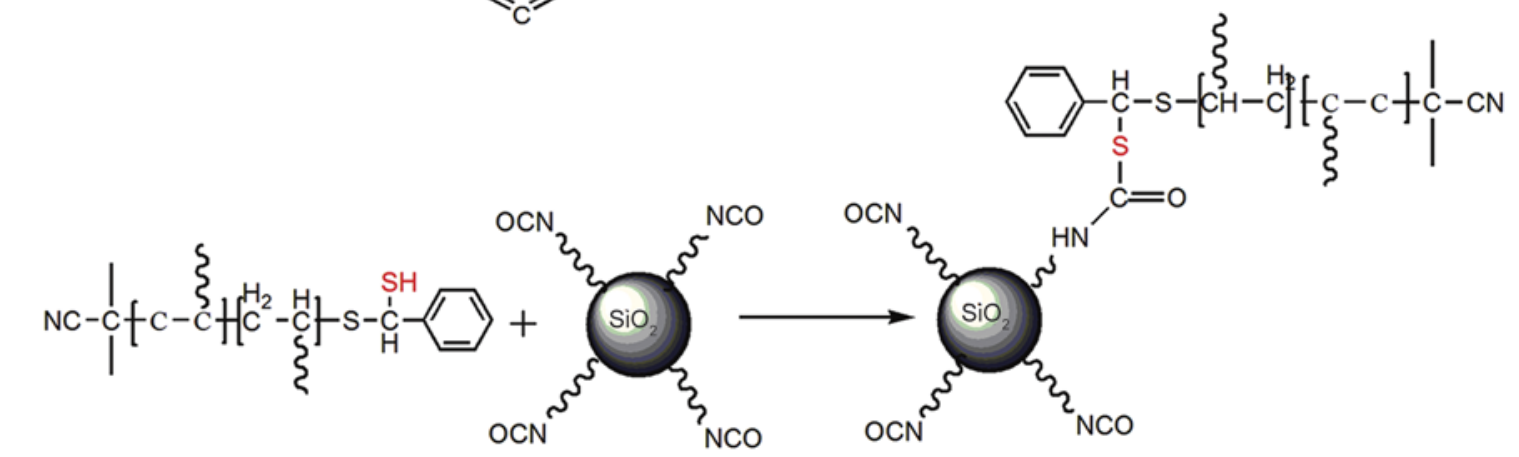

Figure 2. Synthesis route of (a) silica nanosphere modified with TDI, and (b) $\mathrm{SiO}_{2} / \mathrm{P}(7-6-\mathrm{AC})-b$-PNIPAAm

temperature. The contact angles were measured at three different points for each sample surface, and the average values were reported here. The static water contact angles were further measured after the irradiation of UV light at 365 and $254 \mathrm{~nm}$, respectively.

\subsection{Characterization}

The morphologies of functional silica particles were observed using transmission electron microscope (TEM) (JEOL JEM-2000EXII, Japan). FT-IR analysis was used to confirm the TDI functionalized $\mathrm{SiO}_{2}$ particles and P (7-6-AC)- $b$-PNIPAAm grafted with $\mathrm{SiO}_{2}$ particles. All FT-IR spectra were recorded at room temperature on a Magna-IR 760 (Nicolet, USA) spectrometer using 32 scans at an instrument resolution of $4 \mathrm{~cm}^{-1}$. Ultraviolet spectrophotometer (Iambda 35, Perkin Elmer, Germany) was used to confirm the copolymer successfully grafted with functioned $\mathrm{SiO}_{2}$ and the transformation of absorbance under 365 and $254 \mathrm{~nm}$ UV irradiation. Thermal gravimetric analysis (TGA) (TGA 7, Perkin Elmer, Germany) was performed to analyze the weight-loss percent of the organic component. The particles were heated from 20 to $600^{\circ} \mathrm{C}$ at the heating rate of $10^{\circ} \mathrm{C} / \mathrm{min}$ under nitrogen atmosphere with the rate of $50 \mathrm{~mL} / \mathrm{min}$. And the Attension Theta Lite (Attension, Finland) was used to measure the contact angle of the $\mathrm{SiO}_{2}$ particles as prepared.

\section{Results and discussion}

\subsection{Preparation of P(7-6-AC)-b-PNIPAAm by RAFT}

The structures of 7-6-AC, $\mathrm{P}(7-6-\mathrm{AC})$ and $\mathrm{P}(7-6-$ AC)- $b$-PNIPAAm were characterized by ${ }^{1} \mathrm{H}$ NMR. The ${ }^{1} \mathrm{H}$ NMR spectra of the 7-6-AC, $\mathrm{P}(7-6-\mathrm{AC})$ and $\mathrm{P}$ (7-6-AC)-b-PNIPAAm are shown in Figure 3, respectively. Compared with 7-6-AC (Figure 3a), the signals $\left(5.84,6.23\right.$ and $\left.6.40 \mathrm{ppm}\left(\mathrm{CH}_{2}=\mathrm{CH}-\right)\right)$ of $\mathrm{P}(7-6-\mathrm{AC})$ disappear in Figure 3b. It clearly demonstrates that the double bond in the long chain has been polymerized. In Figure $3 \mathrm{c}$, the new signal (7.95 ppm $(\mathrm{O}=\mathrm{C}-\mathrm{N}-\mathrm{H})$ ) could be assigned to the amide group in the repeat unit of PNIPAAm structure introduced into $\mathrm{P}(7-6-\mathrm{AC})-b$-PNIPAAm. The signals of $\mathrm{ppm}=6.2, \mathrm{ppm}=6.6, \mathrm{ppm}=6.8, \mathrm{ppm}=$ $7.3, \mathrm{ppm}=7.6$ were attributed to the coumarin group in 7-6-AC, $\mathrm{P}(7-6-\mathrm{AC})$ and $\mathrm{P}(7-6-\mathrm{AC})-b$-PNIPAAm. All the results indicate that the $\mathrm{P}(7-6-\mathrm{AC})-b-\mathrm{PNI}-$ PAAm with the end group which can easily restore to sulfhydryl has been synthetized successfully.

The P(7-6-AC) $\left(M_{\mathrm{n}}=8100 \mathrm{~g} / \mathrm{mol}, \mathrm{PDI}=1.17\right)$ as the macro-RAFT agent, which reacted with NIPAAm to obtain the block polymer. Gel permeation chromatographic (GPC) curves (Figure 4) demonstrates that there was an increase in the molecular weights (from 8100 to $9400 \mathrm{~g} / \mathrm{mol}$ ) after chain extension. However, the value of PDI increases from 1.17 to 1.22 with the chain extension of the polymer. The 
(a)

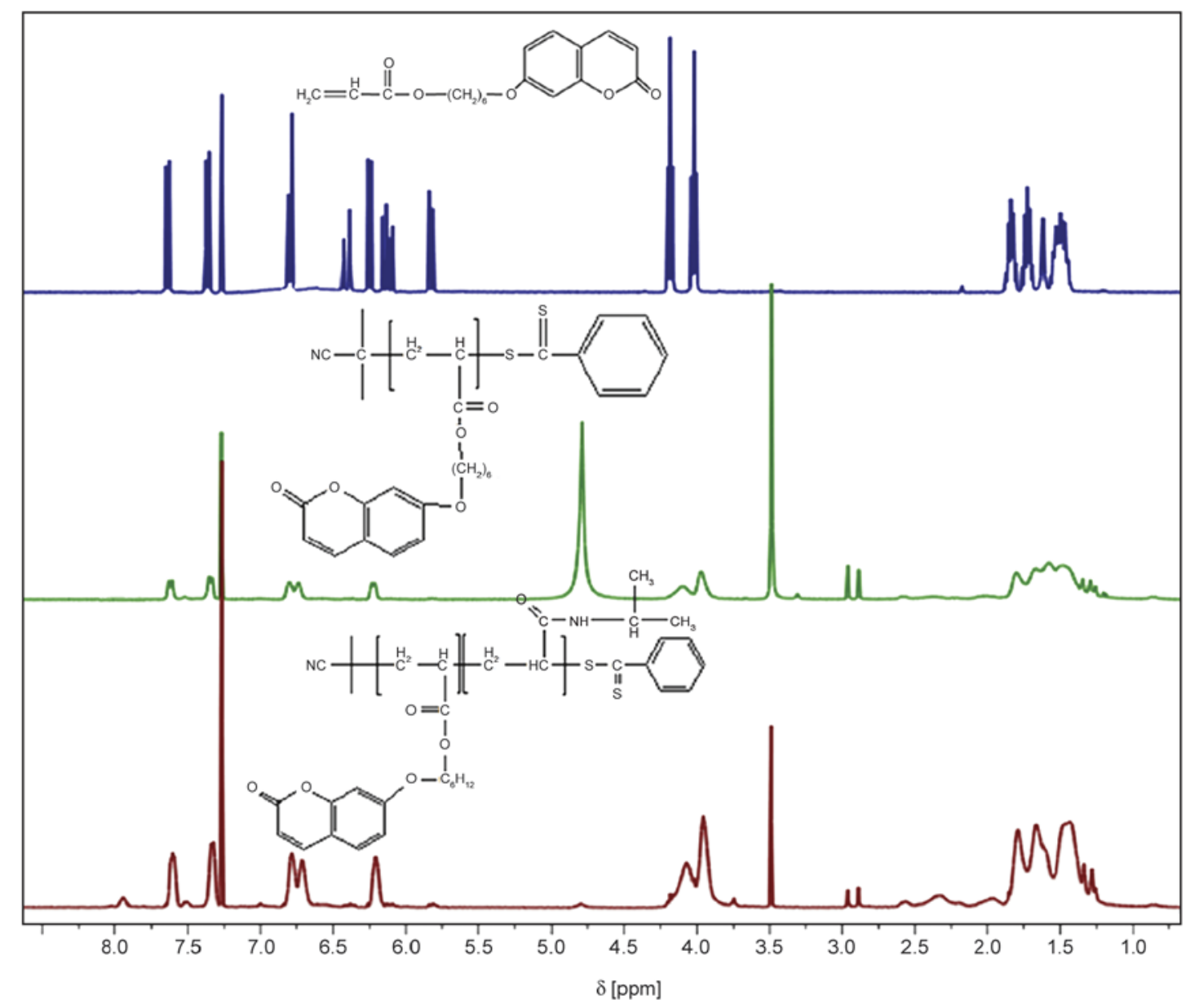

Figure 3. ${ }^{1} \mathrm{H}$ NMR spectra of (a) 7-6-AC, (b) $\mathrm{P}(7-6-\mathrm{AC})$ and (c) $\mathrm{P}$ (7-6-AC)-b-PNIPAAm

increase can be due to the increase of the block and the molecular weight of the $\mathrm{P}(7-6-\mathrm{AC})-b$-PNIPAAm.

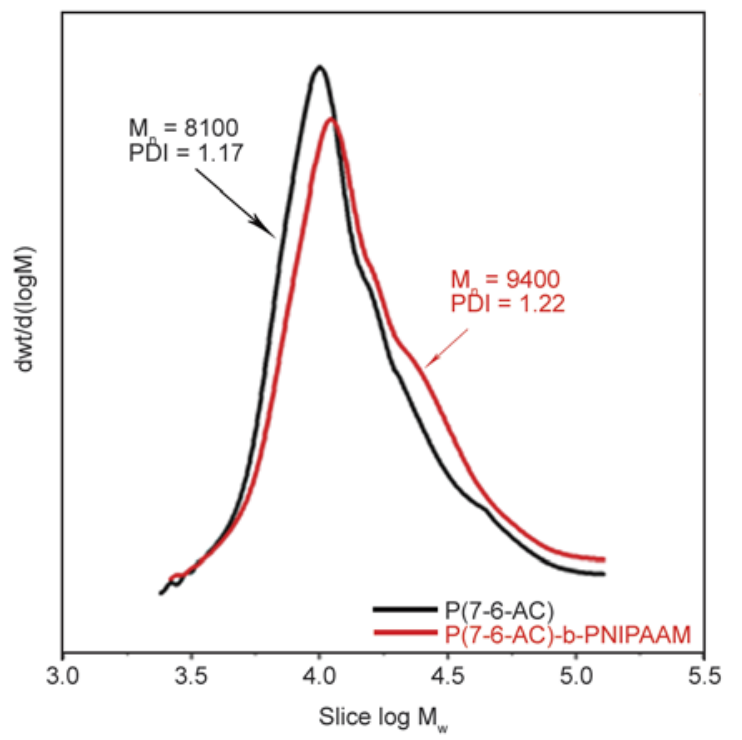

Figure 4. GPC curves of the original macro-RAFT agent $(\mathrm{P}(7-6-\mathrm{AC}))$ and the chain extended block copolymer P(7-6-AC)- $b$-PNIPAAm in THF solution

\subsection{Fabrication of}

$\mathrm{SiO}_{2} / \mathrm{P}(7-6-A C)-b$-PNIPAAm composites

Figure 5 presents the FT-IR spectra (I), contact angles (II) and TGA profile (III) of (a) pure $\mathrm{SiO}_{2}$, (b) $\mathrm{SiO}_{2} / \mathrm{TDI}$ and (c) $\mathrm{SiO}_{2} / \mathrm{P}$ (7-6-AC)- $b$-PNIPAAm, respectively. In Figure 5(I) a, the peaks at $1105 \mathrm{~cm}^{-1}$ and the shoulder part between the bands of 1100 $1300 \mathrm{~cm}^{-1}$ correspond to the concerted ( $\mathrm{Si}-\mathrm{O}-\mathrm{Si}$ ) stretches. Compared with the spectra of pure $\mathrm{SiO}_{2}$, the intensity of the peak at $2276 \mathrm{~cm}^{-1}$ (Figure 5(I)b) corresponded to the characteristic absorption peak of -NCO group, and the typical benzene ring absorption bands at $1500-1600 \mathrm{~cm}^{-1}$ are clearly found, implying that the TDI has been grafted successfully onto the surface of $\mathrm{SiO}_{2}$. The absorption peak of $3167 \mathrm{~cm}^{-1}$ in Figure 5(I)c demonstrate the existence of amide group, and the absorption appearing at $974 \mathrm{~cm}^{-1}$ implies that the $-\mathrm{CH}-\mathrm{CH}_{2}-$ groups existed on the surface of $\mathrm{SiO}_{2}$ nanosphere. These results suggest that $\mathrm{P}(7-6-\mathrm{AC})-b$-PNIPAAm has been successfully grafted onto the surface of $\mathrm{SiO}_{2}$ nanosphere by RAFT and thiol-NCO click chemistry. 

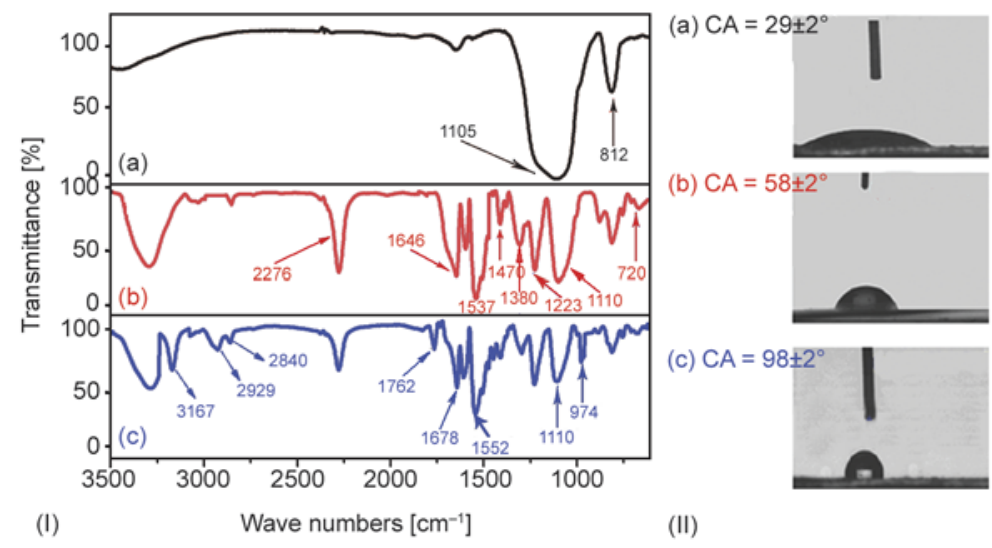

(II)

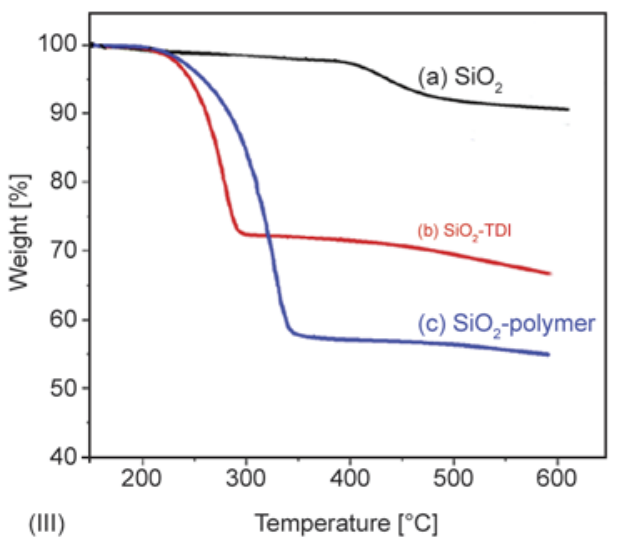

Figure 5. The FT-IR spectra (I), contact angles (II) and TGA (III) profile of (a) pure $\mathrm{SiO}_{2}$, (b) $\mathrm{SiO}_{2} / \mathrm{TDI}$ and (c) $\mathrm{SiO} 2 / \mathrm{P}(7-6-$ AC)- $b$-PNIPAAm, respectively

Moreover, the typical absorption of the cyclic lactones group appears at $1762 \mathrm{~cm}^{-1}$, which further demonstrated that the $\mathrm{SiO}_{2} / \mathrm{P}(7-6-\mathrm{AC})-b$-PNIPAAm composites were synthesized. the characteristic absorptions at 2929 and $2840 \mathrm{~cm}^{-1}$ are assigned to the vibration of $-\mathrm{CH}_{2}-$ groups, the correlative peak of $-\mathrm{CH}_{3}$ group, and the peaks at 1470, 1380, $720 \mathrm{~cm}^{-1}$ can be assigned to the out-of-plane and in plane bending vibration of $-\mathrm{CH}_{3}$ group. Additionally, the absorption peak at $2276 \mathrm{~cm}^{-1}$ (Figure 5(I)c) can be attributed to the residual $-\mathrm{NCO}$ groups remaining on the surface of $\mathrm{SiO}_{2} / \mathrm{TDI}$, which did not react with $-\mathrm{SH}$. The results can also be considered to the identification of the $\mathrm{SiO}_{2} / \mathrm{P}(7-6-\mathrm{AC})-b$ PNIPAAm by the TEM images, which show a coreshell structure.

In Figure 5(II), the contact angles of $\mathrm{SiO}_{2}, \mathrm{SiO}_{2} / \mathrm{TDI}$ and $\mathrm{SiO}_{2} / \mathrm{P}(7-6-\mathrm{AC})-b$-PNIPAAm were $29 \pm 2,58 \pm 2$ and $98 \pm 2^{\circ}$, respectively. The results imply that the wettability has been changed after the modification of TDI and P(7-6-AC)-b-PNIPAAm on the surface of $\mathrm{SiO}_{2}$. Low contact angles $\left(29 \pm 2^{\circ}\right)$ of pure $\mathrm{SiO}_{2}$ can be explained by the fact that many hydrophilic groups (hydroxyl groups) covered on the pure $\mathrm{SiO}_{2}$ surface. As for $\mathrm{SiO}_{2} / \mathrm{TDI}$, the contact angles increases up to $58 \pm 2^{\circ}$ for the hydrophobic group of TDI on the surface of $\mathrm{SiO}_{2}$, which further demonstrated that PDI has been grafted on $\mathrm{SiO}_{2}$. The sulfhydryl group on $\mathrm{P}(7-6-\mathrm{AC})-b$-PNIPAAm as the terminal group can react with the portion of $-\mathrm{NCO}$ group on $\mathrm{SiO}_{2} / \mathrm{TDI}$ surface. Therefore, the $\mathrm{SiO}_{2}$ particles covered with -NCO group and $\mathrm{P}(7-6-\mathrm{AC})-b$-PNIPAAm possess a higher hydrophobic surface and higher contact angles, and the high contact angle $\left(98 \pm 2^{\circ}\right)$ was primarily attributed to P(7-6-AC)- $b$-PNIPAAm, which own lower surface energy than inorganic molecule.
The thermal behavior of the $\mathrm{SiO}_{2}, \mathrm{SiO}_{2} / \mathrm{TDI}$ and $\mathrm{SiO}_{2} / \mathrm{P}(7-6-\mathrm{AC})-b$-PNIPAAm was investigated by TGA in $\mathrm{N}_{2}$ for comparison, which serves to confirm the percentage of the particles surrounding by organic phase. Figure 5(III) shows the TGA analysis of the bare $\mathrm{SiO}_{2}, \mathrm{SiO}_{2}-\mathrm{PDI}$, and $\mathrm{SiO}_{2}-\mathrm{P}(7-6-\mathrm{AC})-b$-PNIPAAm. As shown in Figure 5(III)a, the main temperature regions of weight loss appear in the interval $400-500^{\circ} \mathrm{C}$, which can be assigned to the dehydration condensation reaction of the hydroxyl on the silica surface, and the chemical reaction equations can be expressed as Equation (1) [47]:

$$
\mathrm{Si}-\mathrm{OH}+\mathrm{Si}-\mathrm{OH} \rightarrow-\mathrm{Si}-\mathrm{O}-\mathrm{Si}-+\mathrm{H}_{\mathrm{t}} \mathrm{O}
$$

Figure 5(III)b, 5(III)c describes the thermal behavior of $\mathrm{SiO}_{2} / \mathrm{TDI}$ and $\mathrm{SiO}_{2}-\mathrm{P}(7-6-\mathrm{AC})-b$-PNIPAAm, The results show the weight loss with $4.73 \%$ of $\mathrm{SiO}_{2} / \mathrm{TDI}$ and $\mathrm{SiO}_{2}-\mathrm{P}(7-6-\mathrm{AC})-b$-PNIPAAm was $27.2,41.1 \%$, respectively, and the peak pyrolysis temperatures of $\mathrm{SiO}_{2} / \mathrm{TDI}$ and $\mathrm{SiO}_{2}-\mathrm{P}(7-6-\mathrm{AC})-b$ PNIPAAm are 291.4 and $349.4^{\circ} \mathrm{C}$. According to the reference [48], the surface grafting density of $\mathrm{SiO}_{2-}$ TDI and $\mathrm{SiO}_{2}-\mathrm{P}$ (7-6-AC)- $b$-PNIPAAm was calculated to be about $1.29 \mathrm{mmol} / \mathrm{g}(0.222 \mathrm{~g} / \mathrm{g})$ and $0.02 \mathrm{mmol} / \mathrm{g}(0.188 \mathrm{~g} / \mathrm{g})$ respectively. Obviously, the graft density obtained from 'click chemistry' is higher than that of the traditional and classic method [49, 50], for example $\mathrm{SiO}_{2}$ surface silanization using silane coupling agent.

\subsection{The responsive switch of $\mathrm{SiO}_{2} / \mathrm{P}$ (7-6-AC)-b-PNIPAAm composites}

It is well known that the properties of the block polymer determined by the different ratio of its two blocks. In P(7-6-AC)-b-PNIPAAm, the first block 
$\mathrm{P}(7-6-\mathrm{AC})$ may cause the cross-linking because of the existence of coumarin group. If the ratio of the coumarin block too high, the PDI will out of 1.2 and the cross-linking of the coumarin will change the property of the polymer. For the second block, because of strong hydrophilicity of the amido group, the high ratio of the NIPAAm will enhance the hydrophilicity and the contact angles of the prepared nanoparticles will less than $150^{\circ}$. On the other hand, while the ratio is too low, the thermal-sensitive features are not obvious. In fact, a variety of block polymers with different block unit, such as 10, 15, 20, 25, 30, 50 polymerization units, have been synthesized. The thermal-sensitive characteristics and the contact angles of the $\mathrm{SiO}_{2} / \mathrm{P}(7-6-\mathrm{AC})-b$-PNIPAAm composites with different ratio of $\mathrm{P}(7-6-\mathrm{AC})$ and PNIPAAm is summarized in Table 1. Finally, we choose the largest molecular weight in PDI under
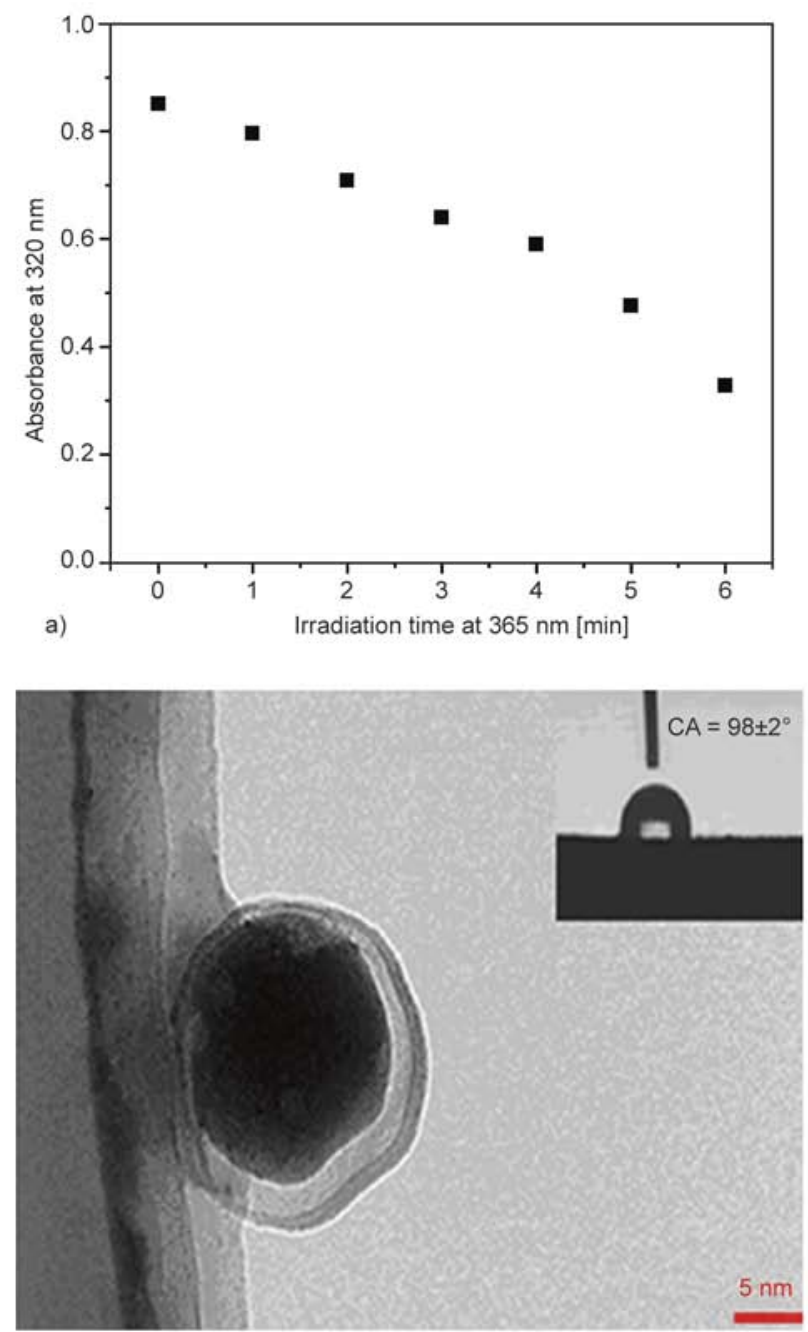

c)
1.2 as the target product $\left(M_{\mathrm{n}}=8100, \mathrm{PDI}=1.17,25\right.$ units) to graft onto the surface of silica nanosphere. The photoresponse of the prepared $\mathrm{SiO}_{2} / \mathrm{P}(7-6-\mathrm{AC})-$ $b$-PNIPAAm was monitored by UV-Vis spectra by the exposure of the clear dilute suspension of $\mathrm{SiO}_{2} /$ $\mathrm{P}$ (7-6-AC)- $b$-PNIPAAm in THF under different wavelengths (365 and $254 \mathrm{~nm}$ ) of UV light. As illustrated in Figure 6a and the absorbed intensity of

Table 1. The thermal-sensitive characteristics and the contact angles of the $\mathrm{SiO}_{2} / \mathrm{P}(7-6-\mathrm{AC})-b$-PNIPAAm composites with different ratio of $\mathrm{P}(7-6-\mathrm{AC})$ and PNIPAAm

\begin{tabular}{|c|c|c|}
\hline $\begin{array}{c}\text { The ratio of } \\
\text { P(7-6-AC) and } \\
\text { PNIPAAm }\end{array}$ & $\begin{array}{c}\text { The thermal- } \\
\text { sensitive } \\
\text { characteristics }\end{array}$ & $\begin{array}{c}\text { The contact angles } \\
\text { of the prepared } \\
\text { nanoparticles }\end{array}$ \\
\hline $30: 5$ & Not obvious & $159 \pm 2^{\circ}$ \\
\hline $30: 10$ & Obvious & $157 \pm 2^{\circ}$ \\
\hline $30: 20$ & Obvious & $148 \pm 2^{\circ}$ \\
\hline $30: 30$ & Obvious & $141 \pm 2^{\circ}$ \\
\hline
\end{tabular}

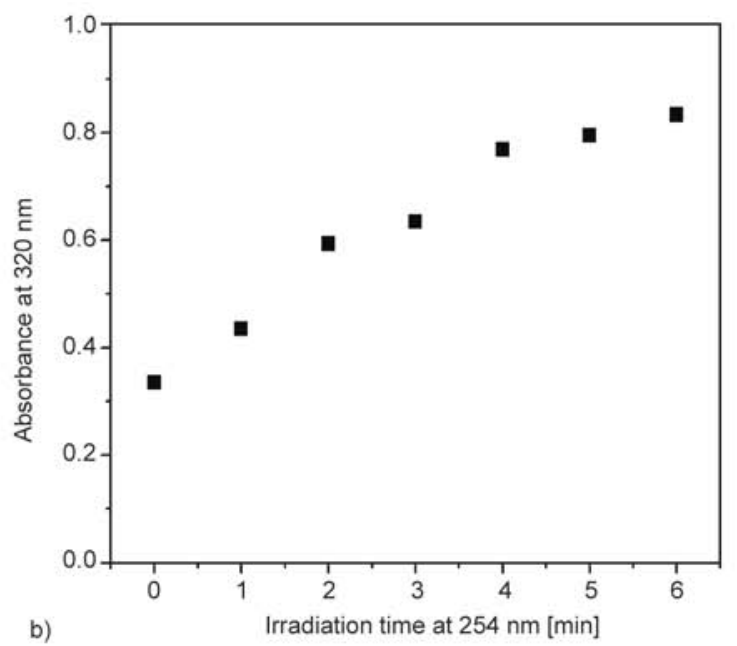

b)

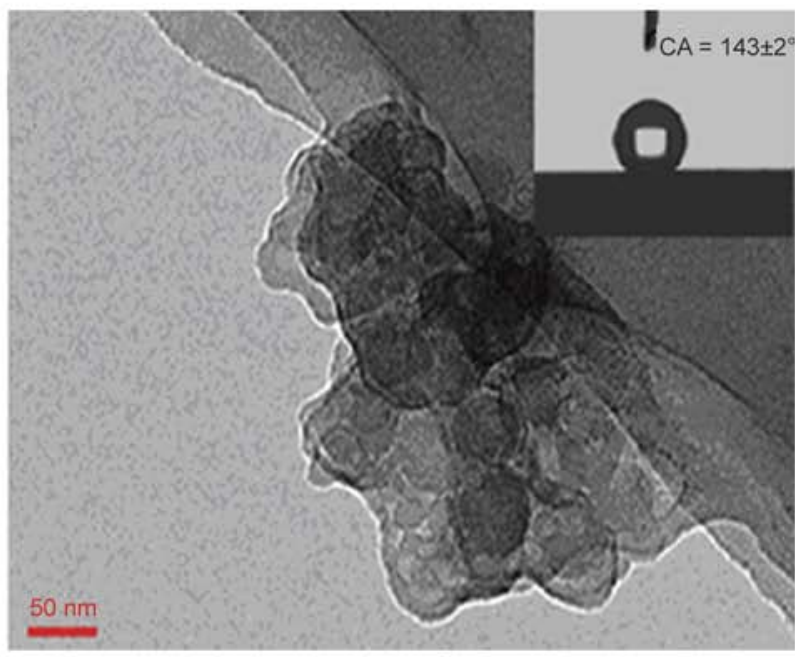

d)

Figure 6. The absorbance at $320 \mathrm{~nm}$ according to the exposure time under the irradiation of $356 \mathrm{~nm}$ (a) and the subsequent irradiation at $\lambda=254 \mathrm{~nm}$ (b); TEM images of the prepared $\mathrm{SiO}_{2} / \mathrm{P}(7-6-\mathrm{AC})-b$-PNIPAAm (c) and its aggregations (d) under $365 \mathrm{~nm}$ irradiation 
coumarin at $320 \mathrm{~nm}$ (characteristic absorption peak) decreases continuously with the exposure time under UV irradiation at $365 \mathrm{~nm}$ (Figure 6b). To the contrast, the absorbance at $320 \mathrm{~nm}$ starts to increase for the photocleavage of coumarin after exposure under the irradiation of $254 \mathrm{~nm}$ UV light (Figure 6b) [51]. This interconversion between hydrophobic and superhydrophobic can attributed to the reversible photodimerization and photocleavage of the coumarin group on $\mathrm{SiO}_{2} / \mathrm{P}$ (7-6-AC)- $b$-PNIPAAm under UV irradiation at different wavelengths.

The reversible photodimerization and photocleavage of $\mathrm{SiO}_{2} / \mathrm{P}$ (7-6-AC)- $b$-PNIPAAm are also studied by TEM. As presented in Figure 6c, a welldefined core-shell structure (20-30 nm) with $\mathrm{SiO}_{2}$ nanospheres as core and block polymer as shell has been observed. It suggested that the $\mathrm{SiO}_{2}$ particles were surrounded by P(7-6-AC)-b-PNIPAAm with a thickness of about $3 \mathrm{~nm}$. Moreover, the silica nanoparticles modified by $\mathrm{P}(7-6-\mathrm{AC})-b$-PNIPAAm is dispersive spherical particle with the size of $50 \mathrm{~nm}$ before the exposure of UV light. On the contrary, the $\mathrm{SiO}_{2} / \mathrm{P}(7-6-\mathrm{AC})-b$-PNIPAAm nanoparticle aggregated after the irradiation of UV light $(365 \mathrm{~nm})$, and the size of the aggregations increased up to $300 \mathrm{~nm}$, suggesting that $\mathrm{SiO}_{2} / \mathrm{P}(7-6-\mathrm{AC})-b$-PNIPAAm have been cross-linked together by the photodimerization of the coumarin under UV light at $365 \mathrm{~nm}$ irradiation (Figure 6d).

Figure 7 shows AFM and SEM images of the single and aggregations of $\mathrm{SiO}_{2} / \mathrm{P}(7-6-\mathrm{AC})-b$-PNIPAAm. Compared with the results of TEM, the aggregations of the $\mathrm{SiO}_{2} / \mathrm{P}$ (7-6-AC)- $b$-PNIPAAm were also observed by AFM and SEM (Figure 7b and 7d) [52]. On Figure 7a, we can find that the $\mathrm{SiO}_{2} / \mathrm{P}(7-6-\mathrm{AC})$ $b$-PNIPAAm disperse with each other, but at the irradiation of $365 \mathrm{~nm}$, the $\mathrm{SiO}_{2} / \mathrm{P}(7-6-\mathrm{AC})-b$-PNIPAAm aggregate together (Figure $7 \mathrm{~b}$ ), which can be due to the photodimerization of the coumarin groups. Therefore, we can find the same result on the SEM images (Figure 7c and Figure 7d). And a great number of cavities have also been constructed among the $\mathrm{SiO}_{2} / \mathrm{P}(7-6-\mathrm{AC})-b$-PNIPAAm in the process of the UV irradiation at $365 \mathrm{~nm}$.

The agglomeration of the prepared $\mathrm{SiO}_{2} / \mathrm{P}(7-6-\mathrm{AC})-$ $b$-PNIPAAm caused by temperature and UV light are also investigated by dynamic light scattering (DLS). Figure $8 \mathrm{~b}$ shows the size of $\mathrm{SiO}_{2} / \mathrm{P}(7-6-\mathrm{AC})-b$ PNIPAAm based on DLS results changed with temperature and the UV irradiation at $365 \mathrm{~nm}$. As shown in Figure 8a, the radius of hydration of the $\mathrm{SiO}_{2} / \mathrm{P}(7-$ 6-AC)- $b$-PNIPAAm were about $50 \mathrm{~nm}$, while the temperature rises to $35^{\circ} \mathrm{C}$, the radius of hydration increases up to $90 \mathrm{~nm}$. The results indicate that the block polymer around the silica nanosphere is responsible for temperature, and the formation of the aggregates changed with temperature. Compared with the original $\mathrm{SiO}_{2} / \mathrm{P}(7-6-\mathrm{AC})-b$-PNIPAAm nanosphere, when the temperature rise to $35^{\circ} \mathrm{C}$, the size of the $\mathrm{SiO}_{2} / \mathrm{P}(7-6-\mathrm{AC})-b$-PNIPAAm nanosphere is up to 90 from $50 \mathrm{~nm}$. On the other hand, the size of the $\mathrm{SiO}_{2} / \mathrm{P}(7-6-\mathrm{AC})-b$-PNIPAAm nanosphere after the UV irradiation at $365 \mathrm{~nm}$ is up to $350 \mathrm{~nm}\left(25^{\circ} \mathrm{C}\right)$ from $50 \mathrm{~nm}$, and further increased to $530 \mathrm{~nm}$ after the temperature rising to $35^{\circ} \mathrm{C}$ (Figure 6b), which can be attributed to the crosslinking of the coumarin after photodimerization. The data of DLS are consistent with the results of TEM, and it also shows the same results with the images of atomic force microscope (AFM).

The mechanism of photo-sensitive and thermal-sensitive of $\mathrm{SiO}_{2} / \mathrm{P}(7-6-\mathrm{AC})-b$-PNIPAAm is proposed in Figure 9. The photodimerization of the coumarins is the primary factor for photo-sensitivity, and the formation of cyclobutane rings $([2 \pi+2 \pi]$ s cycloaddition) (Figure 9a) leads to the aggregation of $\mathrm{SiO}_{2} /$ P(7-6-AC)- $b$-PNIPAAm, which will be further illustrated by TEM. In general, there are two main mechanisms for the explanation of the thermal-sensitivity of PNIPAAm. One is the change of the temperature leading to the change of the polymer structure transition from linear structure to a nearly spherical structure [53]. Another one is the formation and rupture of the hydrogen bonds [54]. In $\mathrm{SiO}_{2} / \mathrm{P}$ (7-6AC)- $b$-PNIPAAm, we think that the thermal-sensitivity can be mostly attributed to the formation and rupture of hydrogen bonds between water and amide (Figure 9b). It is favorable for the formation of hydrogen bonds between the water molecules and amide bond under low temperature, while the hydrogen bonds are broken under high temperature.

In general, contact angle (CA) is used to estimate the wettability of a solid surface. Figure 10 describes the changes of contact angles and the reversible wettability transitions of the surface of $\mathrm{SiO}_{2} / \mathrm{P}(7-6-\mathrm{AC})-b$ PNIPAAm on glass slide by alternating the temperature and UV irradiations at the wavelengths of 365 and $254 \mathrm{~nm}$. Obviously, the $\mathrm{SiO}_{2}$ particles grafted with block polymer exhibit the hydrophobic behavior $\left(\mathrm{CA}=98 \pm 2^{\circ}\right.$ Figure 10 a) below the lower criti- 


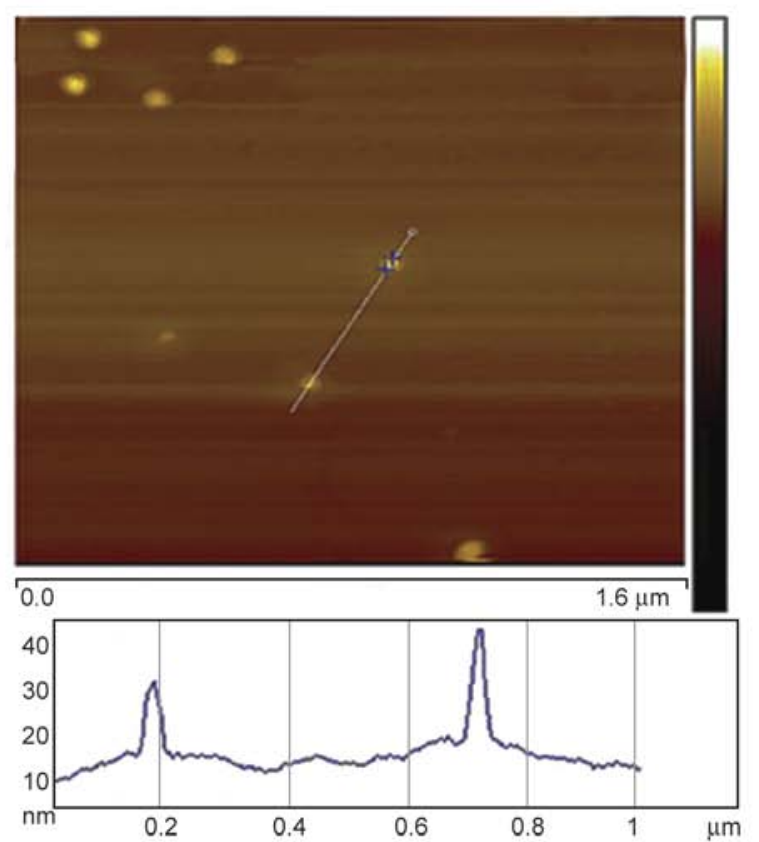

a)

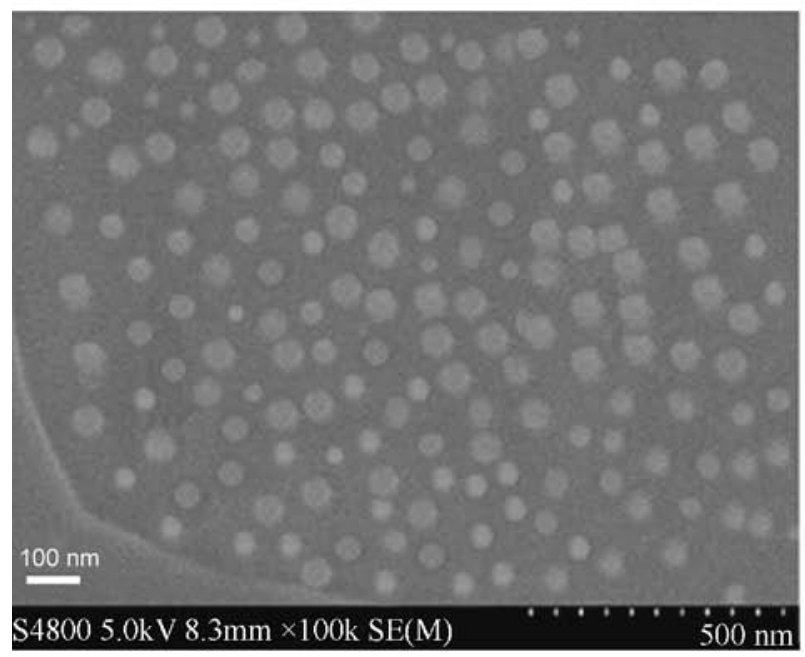

c)
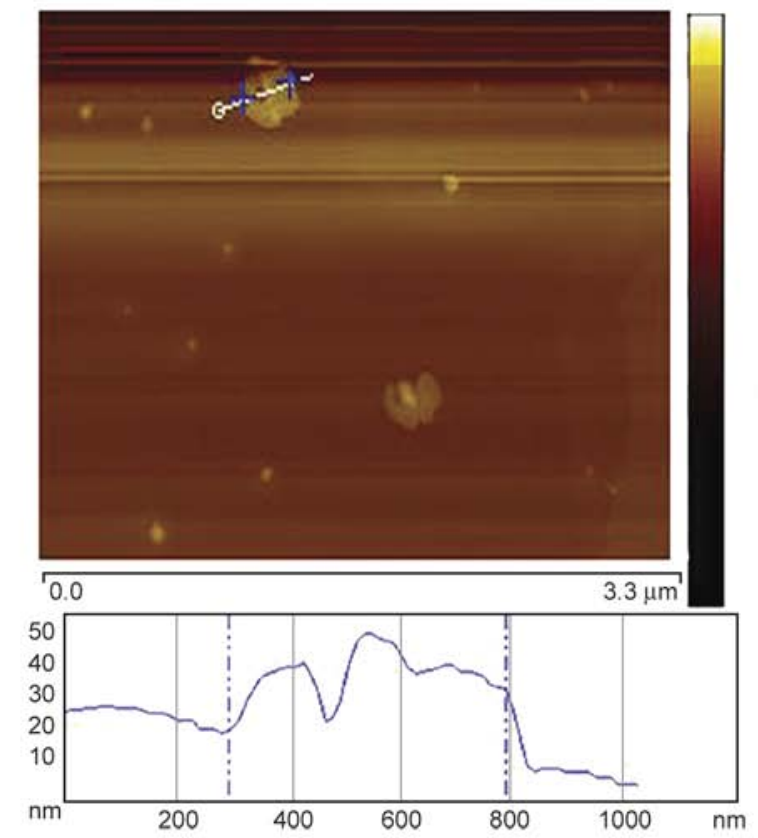

b)

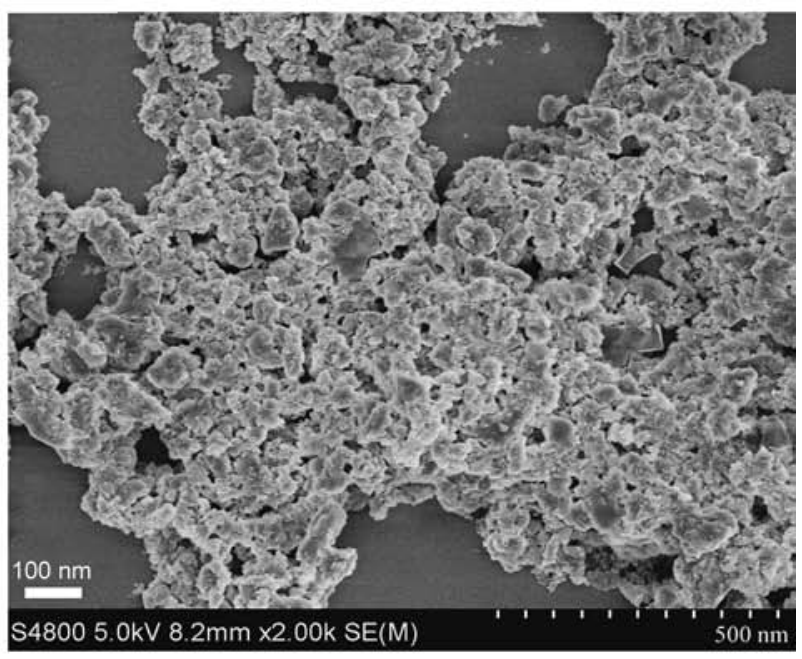

d)

Figure 7. The $\operatorname{AFM}(a, b)$ and $\operatorname{SEM}(c, d)$ images of $\mathrm{SiO}_{2} / \mathrm{P}(7-6-\mathrm{AC})-b$-PNIPAAm upon 254 and 365 nm UV light irradiation, respectively
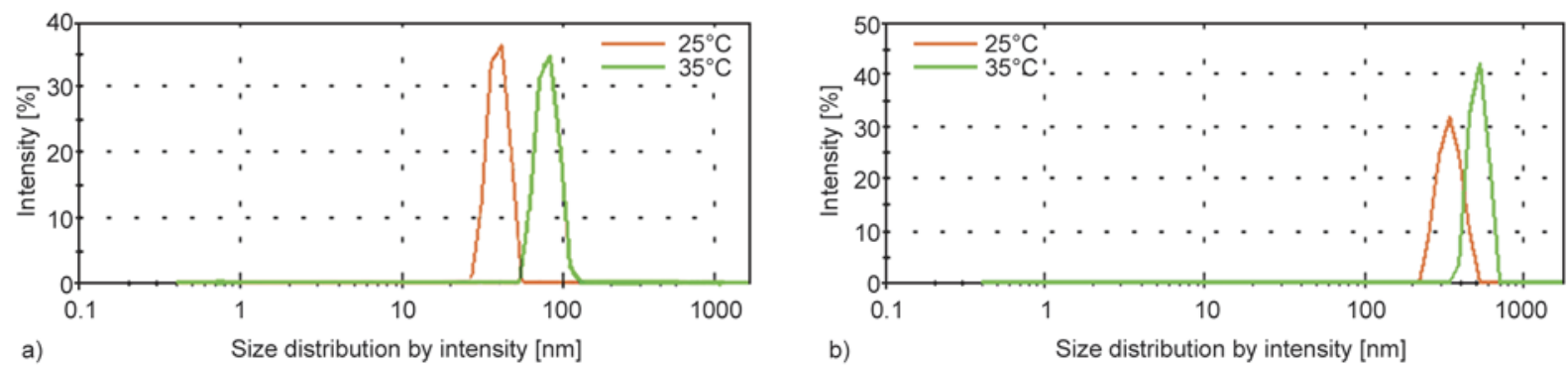

Figure 8. The size distribution of $\mathrm{SiO}_{2} / \mathrm{P}(7-6-\mathrm{AC})-b$-PNIPAAm nanoparticles (a) UV light at $254 \mathrm{~nm}$ and (b) UV light at $365 \mathrm{~nm}$

cal solution temperature $\left(\operatorname{LCST}=32^{\circ} \mathrm{C}\right)$. However, the CA increased evidently to $137 \pm 2^{\circ}$ (Figure 10b) when the temperature was up to $40^{\circ} \mathrm{C}$, and the con- tact angle can further increase once again to $157 \pm 2^{\circ}$ (Figure 10d) after UV irradiation at $365 \mathrm{~nm}$, which shows the superhydrophobic property. On the other 


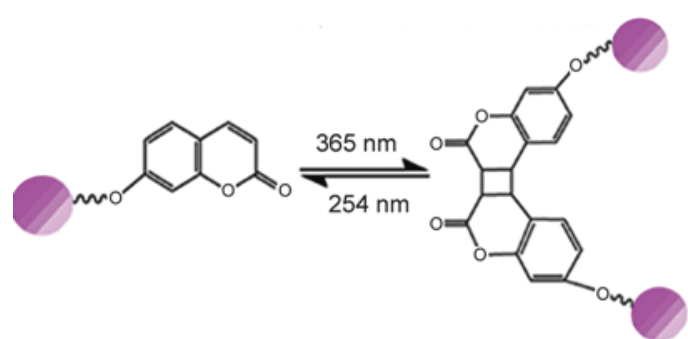

a)

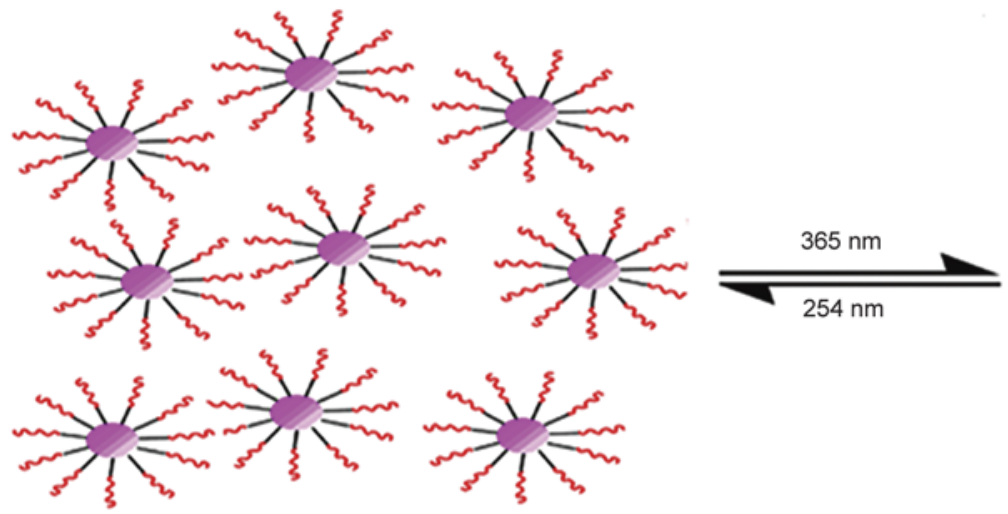

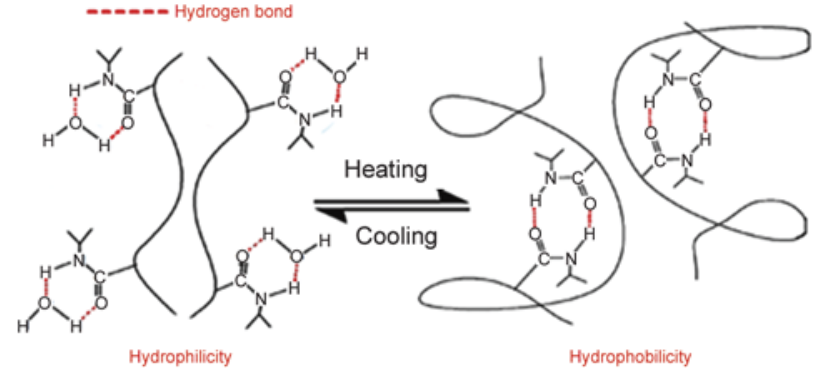

b)

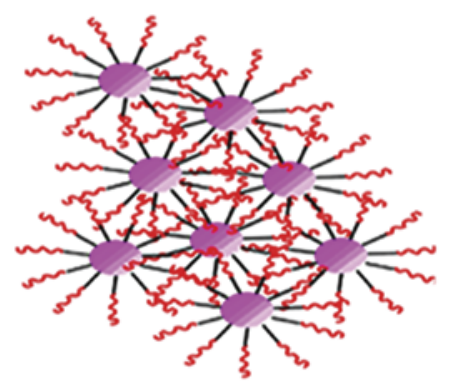

c)

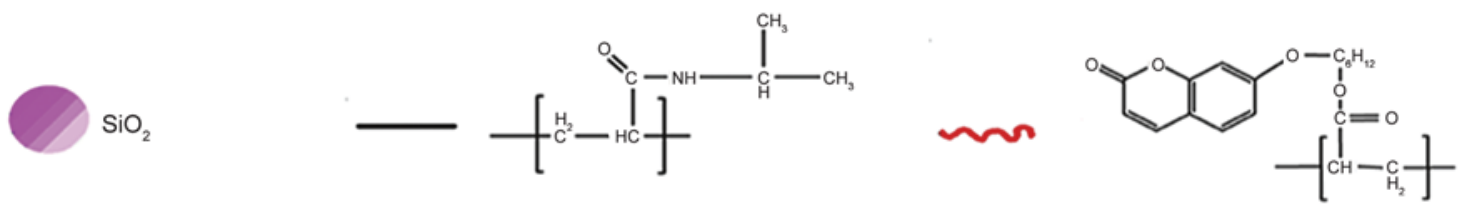

Figure 9. The mechanism for photoreaction and thermal-sensitive of the $\mathrm{SiO}_{2} / \mathrm{P}$ (7-6-AC)- $b$-PNIPAAm: (a) photodimerization of coumarin, (b) the thermal-sensitive mechanism of PNIPAAm, (c) the morphological characteristics of the prepared nanoparticles under different UV irradiation

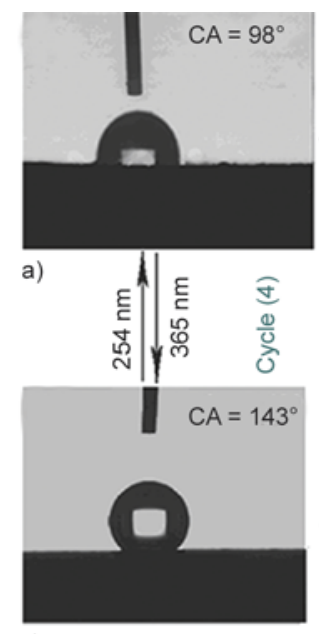

c)
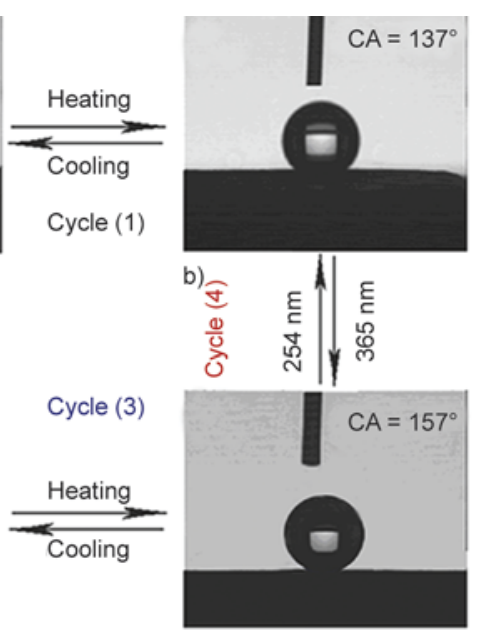

d)

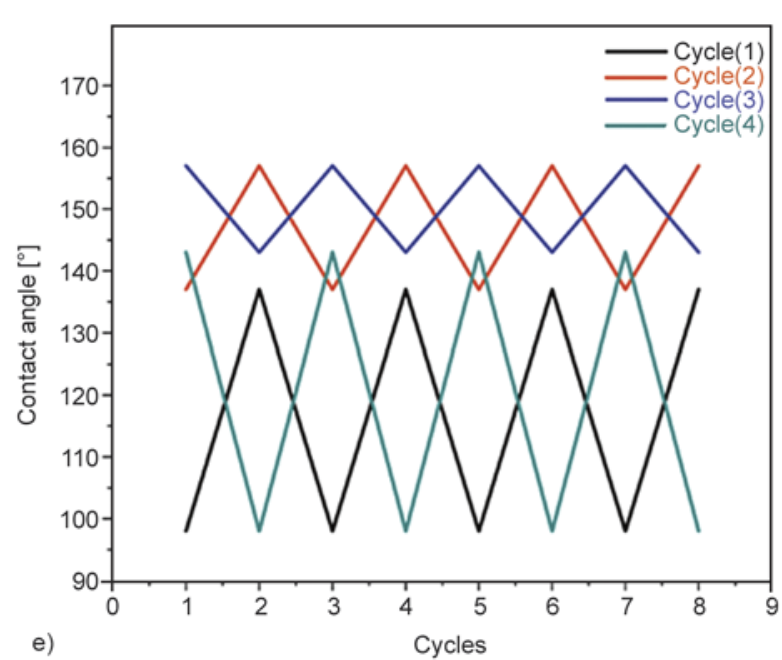

Figure 10. The changes of contact angles (a)-(d) and the reversible wettability transitions (e) of the surface of $\mathrm{SiO}_{2} / \mathrm{P}(7-6-$ AC)- $b$-PNIPAAm particles on glass slide by alternating the temperature and UV irradiations at the wavelengths of 365 and $254 \mathrm{~nm}$. The interval time of each cycle is five days.

hand, we change the order of the stimulation, first irradiating at $365 \mathrm{~nm}$ and then heating to $40^{\circ} \mathrm{C}$, the same result $\left(157 \pm 2^{\circ}\right)$ can be obtained. It is noted that the superhydrophobic surface can return to the orig- inal state by changing temperature $\left(143 \pm 2^{\circ}\right)$ and using UV irradiations at the wavelengths of $254 \mathrm{~nm}$. The results suggest that the surface with the reversible wettability transitions properties has been acquired 
by $\mathrm{SiO}_{2} / \mathrm{P}(7-6-\mathrm{AC})-b-\mathrm{PNIPAAm}$ particles. To explore the thermal-sensitive and photo-sensitive behavior of the surface, cycles between hydrophobic and superhydrophobic are shown in Figure 10e. We repeatedly irradiated the particle surface with alternating UV light at 365 and $254 \mathrm{~nm}$, heating and cooling, and measured the value of the CA as shown in Figure 10e. These results prove that the surface wettability can be reversibly tuned for several cycles. The results show excellent reversibility and a quick transformation between hydrophobicity and superhydrophobicity. Each cycle lasts only several minutes. It was reported that PNIPAAm [55] shows its LCST at $32^{\circ} \mathrm{C}$ in aqueous solution. The hydrogen bond is formed between the water and $\mathrm{N}$-isopmpylacrylamide group when the temperature under the LCST, and it will display the hydrophilic properties. Upon heating, the predominantly intermolecular hydrogen bonding between the PNIPAAm chains and water molecules, which contributes to the hydrophilicity and relaxed PNIPAAm chains, is replaced by intramolecular hydrogen bonding between $\mathrm{C}=\mathrm{O}$ and $\mathrm{N}-\mathrm{H}$ groups along the PNIPAAm chains. This results in compact and collapsed chains that interact minimally with water and thus exhibit hydrophobicity.(Figure 6b).

$\mathrm{N}$-isopmpylacrylamide group becomes exposed and leads to a low surface free energy and large water CAs, and the surface showed the hydrophobic property. Oppositely, the hydrogen bond is formed between water and amide, shown its hydrophilicity of as prepared $\mathrm{SiO}_{2}$ particles at the temperature lower than $32^{\circ} \mathrm{C}$. The photo-sensitive behavior of the surface can be mainly attributed to the coumarin group in the block polymer. At the irradiation of $365 \mathrm{~nm}$, the coumarin groups crosslink with each other and form the disordered structure surrounding the silica.

The TEM results (Figure 6c) have demonstrated that a well-defined core-shell structure with $\mathrm{SiO}_{2}$ as core and block polymer as shell had been constructed. Therefore, the particles convert into a series of aggregations and the air trapping forming among the aggregations at the same time after UV irradiation at $365 \mathrm{~nm}$, which will result in the construction of the hierarchical structure [56].

According to the results observed from AFM and SEM images (Figure 8), the surface can be constructed a hierarchical structure for the formation of a series of branched and rugby-ball-like nanoparti- cles, which indicates that this hierarchical structure has the largest roughness. On the other hand, 7-(6(acryloyloxy) hexyloxy) coumarin possess a lower surface energy for the alkyl chains, which may affect the hydrophobic property of the coatings. As for the thermal-sensitivity, the oxygen groups on the prepared nanoparticles may be wrapped with alkyl chains and be trapped between particles after $365 \mathrm{~nm}$ UV irradiation to avoid forming hydrogen bonds with water. As a result, the CA increases with irradiation time. After photocleavage of the dimers, there is no chemical bonding between the prepared nanoparticles, and water molecules interact with oxygen groups by forming hydrogen bonds to decrease the CA.

The Wenzel and Cassie mode can explain well why the surface switches from hydrophobicity to superhydrophobicity after the irradiation of UV at $365 \mathrm{~nm}$. And it also demonstrates that the mutual transformation between Wenzel model and Cassie model can be occurred via UV irradiation. The Wenzel model can also be used to explain the static contact angle. As described by Wenzel's Equation (2) [57]:

$\cos \theta=r \cos \theta_{\mathrm{r}}$

where is the roughness coefficient and the $\theta_{\mathrm{Y}}$ is the static contact angle calculated by Young's equation. After the $365 \mathrm{~nm}$ UV irradiation, the rough surface comes into contact with water, air trapping in the rough area may occur, which would contribute greatly to the increase of hydrophobicity. By now, because of the air trapping in the trough area, the Cassie model was used to calculate the static contact angle. The Cassie's equation can by described by Equation (3):

$\cos \theta=f \cos \theta_{\mathrm{Y}}-(1-f)$

where $f$ is the fraction of the liquid-solid interface, while $(1-f)$ is the air-liquid interface. And the air trapping would contribute greatly to the increase of hydrophobicity.

\section{Conclusions}

In conclusion, a stable superhydrophobic surface with thermal- and photo-sensitivity was fabricated successfully by a facile approach which combined technology of RAFT with click-chemistry. The $\mathrm{SiO}_{2}$ particles as prepared form the air trapping by the photoisomerization of coumarin groups under $365 \mathrm{~nm}$ UV irradiation along with the Wenzel Cassie 
transition, and the formation and rupture of hydrogen bond between amide and water were controlled by the changing of temperature, all resulting in the CA changing from $98 \pm 2$ to $157 \pm 2^{\circ}$. The repeated experiments of the CA changing indicate that the surface wettability can be transformed between hydrophobicity to superhydrophobicity reversibly, indicating that the surface has good stability. This novel method using RAFT technology to synthesize multiple responsive block polymers will be widely used in fabricating multiple responsive superhydrophobic surfaces. The multiple responsive superhydrophobic surfaces have great potential application in the controlled release of drugs fields and the fabrication of responsive switches.

\section{Acknowledgements}

This work was supported by the Research Fund for the Doctoral Program of Higher Education of China (20120161110024) and the National Natural Science Foundation of China (No. J1210040).

\section{References}

[1] Boinovich L., Emelyanenko A. M., Pashinin A. S.: Analysis of long-term durability of superhydrophobic properties under continuous contact with water. ACS Applied Materials and Interfaces, 2, 1754-1758 (2010). DOI: $10.1021 / \mathrm{am} 100241 \mathrm{~s}$

[2] Sun T., Feng L., Gao X., Jiang L.: Bioinspired surfaces with special wettability. Accounts of Chemical Research, 38, 644-652 (2005).

DOI: $10.1021 / \operatorname{ar} 040224 \mathrm{c}$

[3] Verplanck N., Coffinier Y., Thomy V., Boukherroub R.: Wettability switching techniques on superhydrophobic surfaces. Nanoscale Research Letters, 2, 577596 (2007).

DOI: $10.1007 / \mathrm{s} 11671-007-9102-4$

[4] Liu Y., Mu L., Liu B., Kong J.: Controlled switchable surface. Chemistry: A European Journal, 11, 26222631 (2005).

DOI: $10.1002 /$ chem.200400931

[5] Wang X., Gao M.: A facile route for preparing rhabdophane rare earth phosphate nanorods. Journal of Materials Chemistry, 16, 1360-1365 (2006).

DOI: 10.1039/B517179B

[6] Han J. T., Lee D. H., Ryu C. Y., Cho K.: Fabrication of superhydrophobic surface from a supramolecular organosilane with quadruple hydrogen bonding. Journal of the American Chemical Society, 126, 47964797 (2004). DOI: $10.1021 /$ ja0499400

[7] Russell T. P.: Surface-responsive materials. Science, 297, 964-968 (2002).

DOI: $\underline{10.1126 / \text { science. } 1075997}$
[8] Feng C. L., Zhang Y. J., Jin J., Song Y. L., Xie L., Qu G., Jiang L., Zhu D.: Reversible wettability of photoresponsive fluorine-containing azobenzene polymer in Langmuir-Blodgett films. Langmuir, 17, 4593-4598 (2001).

DOI: $10.1021 / 1 \mathrm{a} 010071 \mathrm{r}$

[9] Calliesa M., Quéré D.: On water repellency. Soft Matter, 1, 55-61 (2005).

DOI: 10.1039/B501657F

[10] Nosonovsky M., Bhushan B.: Hierarchical roughness makes superhydrophobic states stable. Microelectronic Engineering, 84, 382-386 (2007).

DOI: $10.1016 /$ j.mee.2006.10.054

[11] Wang M., Chen C., Ma J., Xu J.: Preparation of superhydrophobic cauliflower-like silica nanospheres with tunable water adhesion. Journal of Materials Chemistry, 21, 6962-6966 (2011). DOI: $10.1039 / \mathrm{C} 1 \mathrm{JM} 10283 \mathrm{D}$

[12] Li J., Liu X., Ye Y., Zhou H., Chen J.: Fabrication of superhydrophobic $\mathrm{CuO}$ surfaces with tunable water adhesion. Journal of Physical Chemistry C, 115, 47264730 (2011).

DOI: $10.1021 / j p 111296 n$

[13] Feng X. J., Jiang L.: Design and creation of superwetting/antiwetting surfaces. Advanced Materials, 18, 3063-3078 (2006). DOI: $10.1002 /$ adma.200501961

[14] Azzaroni O., Brown A. A., Huck W. T. S.: Tunable wettability by clicking counterions into polyelectrolyte brushes. Advanced Materials, 19, 151-155 (2007).

DOI: $10.1002 / \mathrm{adma} .200601257$

[15] Fan X., Jiang L.: Bio-inspired, smart, multiscale interfacial materials. Advanced Materials, 20, 2842-2858 (2008).

DOI: $10.1002 / \mathrm{adma} .200800836$

[16] Wang S., Song Y., Jiang L.: Photoresponsive surfaces with controllable wettability. Journal of Photochemistry and Photobiology C: Photochemistry Reviews, 8, 18-29 (2007).

DOI: $10.1016 /$ j.jphotochemrev.2007.03.001

[17] Chen H., Pan S., Xiong Y., Peng C., Pang X., Li L., Xiong Y., Xu W.: Preparation of thermo-responsive superhydrophobic $\mathrm{TiO}_{2} /$ poly( $N$-isopropylacrylamide) microspheres. Applied Surface Science, 258, 95059509 (2012).

DOI: $10.1016 /$ j.apsusc.2012.04.096

[18] Wu D., Wu S-Z., Chen Q-D., Zhang Y-L, Yao J., Yao X., Niu L-G., Wang J-N., Jiang L., Sun H-B.: Curvaturedriven reversible in situ switching between pinned and roll-down superhydrophobic states for water droplet transportation. Advanced Materials, 23, 545-549 (2011). DOI: $10.1002 / \mathrm{adma} .201001688$

[19] Feng N., Zhao H., Zhan J., Tia D., Li H.: Switchable wettability sensor for ion pairs based on calix[4]azacrown clicking. Organic Letters, 14, 1958-1961 (2012). DOI: $10.1021 / \mathrm{ol} 203226 \mathrm{q}$ 
[20] Bi H., Yin K., Xie X., Zhou Y., Wan N., Xu F., Banhart F., Sun L., Ruoff R. S.: Low temperature casting of graphene with high compressive strength. Advanced Materials, 22, 5125-5128 (2012).

DOI: $10.1002 /$ adma.201201519

[21] Stayton P. S., Shimoboji T., Long C., Chilkoti A., Ghen G., Harris J. M., Hoffman A. S.: Control of proteinligand recognition using a stimuli-responsive polymer. Nature, 378, 472-474 (1995).

DOI: $10.1038 / 378472 \mathrm{a} 0$

[22] Dai S., Ravi P., Tam K. C.: Thermo- and photo-responsive polymeric systems. Soft Matter, 5, 2513-2533 (2009).

DOI: $10.1039 / \mathrm{B} 820044 \mathrm{~K}$

[23] Jochum F. D., zur Borg L., Roth P. J., Theato P.: Thermoand light-responsive polymers containing photoswitchable azobenzene end groups. Macromolecules, 42, 7854-7862 (2009).

DOI: $10.1021 / \mathrm{ma} 901295 \mathrm{f}$

[24] Jochum F. D., Theato P.: Temperature and light sensitive copolymers containing azobenzene moieties prepared via a polymer analogous reaction. Polymer, 50, 3079-3085 (2009).

DOI: $10.1016 /$ j.polymer.2009.05.041

[25] Xia F., Feng L., Wang S., Sun T., Song W., Jiang W., Jiang L.: Dual-responsive surfaces that switch between superhydrophilicity and superhydrophobicity. Advanced Materials, 18, 432-436 (2006).

DOI: 10.1002/adma.200501772

[26] Das S., Ranjan P., Maiti P. S., Singh G., Leitus G., Klajn R.: Dual-responsive nanoparticles and their selfassembly. Advanced Materials, 25, 422-426 (2013). DOI: $10.1002 / \mathrm{adma} .201201734$

[27] Liu H., Li Y., Sun K., Fan J., Zhang P., Meng J., Wang S., Jiang L.: Dual-responsive surfaces modified with phenylboronic acid-containing polymer brush to reversibly capture and release cancer cells. Journal of the American Chemical Society, 135, 7603-7609 (2013).

DOI: $10.1021 / \mathrm{ja} 401000 \mathrm{~m}$

[28] Fu Q., Rao G. V. R., Basame S. B., Keller D. J., Artyushkova K., Fulghum J. E. G., López P.: Reversible control of free energy and topography of nanostructured surfaces. Journal of the American Chemical Society, 126, 8904-8905 (2004).

DOI: $10.1021 /$ ja047895q

[29] Liu Y., Zhao M., Bergbreiter D. E., Crooks R. M.: pHswitchable, ultrathin permselective membranes prepared from multilayer polymer composites. Journal of the American Chemical Society, 119, 8720-8721 (1997).

DOI: $10.1021 /$ ja972075h

[30] Roy D., Cambre J. N., Sumerlin B. S.: Future perspectives and recent advances in stimuli-responsive materials. Progress in Polymer Science, 35, 278-301 (2010).

DOI: $10.1016 /$ j.progpolymsci.2009.10.008
[31] Rosario R., Gust D., Garcia A. A., Hayes M., Taraci J. L., Clement T., Dailey J. W., Picraux S. T.: Lotus effect amplifies light-induced contact angle switching. Journal of Physical Chemistry B, 108, 12640-12642 (2004). DOI: $10.1021 /$ jp0473568

[32] Li L., Pan S., Pang X., Chen H., Hu D., Ke L., Xiong Y., Xu W.: Fabrication of a coumarin-driven switchable superhydrophobic silica surface by photochemistry. Soft Matter, 8, 7357-7360 (2012).

DOI: $10.1039 / \mathrm{c} 2 \mathrm{sm} 25888 \mathrm{a}$

[33] Pang X., Pan S., Feng S., Chen H., Li L., Su X., Xiong Y., Xu W.: Photoreversible superhydrophobic surfaces with switchable sticky-rolling state of water droplets. Macromolecular Materials and Engineering, 297, 979-984 (2012).

DOI: 10.1002/mame.201100386

[34] Lim M. H., Stein A.: Comparative studies of grafting and direct syntheses of inorganic-organic hybrid mesoporous materials. Chemistry of Materials, 11, 3285-3295 (1999).

DOI: $10.1021 / \mathrm{cm} 990369 \mathrm{r}$

[35] Peng J., Yu P., Zeng S., Liu X., Chen J., Xu W.: Application of click chemistry in the fabrication of cactuslike hierarchical particulates for sticky superhydrophobic surfaces. Journal of Physical Chemistry C, 114, 5926-5931 (2010).

DOI: $10.1021 / \mathrm{jp} 909430 \mathrm{z}$

[36] Liu R., Guo Y., Oldusote G., Qu F., Priestley R. D.: Core-shell $\mathrm{Fe}_{3} \mathrm{O}_{4}$ polydopamine nanoparticles serve multipurpose as drug carrier, catalyst support and carbon adsorbent. ACS Applied Materials and Interfaces, 18, 9167-9171 (2013). DOI: $10.1021 / \mathrm{am} 402585 \mathrm{y}$

[37] Kehrlösser D., Träger J., Kim H-C., Hampp N.: Synthesis and photochemistry of coumarin-based selfassembled monolayers on silicon oxide surfaces. Langmuir, 26, 3878-3882 (2010).

DOI: $10.1021 / 1 \mathrm{la} 903433 \mathrm{r}$

[38] Liu J-G., Nakamura Y., Suzuki Y., Shibasaki Y., Ando S., Ueda M.: Highly refractive and transparent polyimides derived from $4,4^{\prime}$ - $[m$-sulfonylbis(phenylenesulfanyl)]diphthalic anhydride and various sulfur-containing aromatic diamines. Macromolecules, 40, 7902-7907 (2007). DOI: $10.1021 / \mathrm{ma} 0713714$

[39] Babin J., Pelletier M., Lepage M., Allard J-F., Morris D., Zhao Y.: A new two-photon-sensitive block copolymer nanocarrier. Angewandte Chemie International Edition, 48, 3329-3332 (2009).

DOI: $10.1002 /$ anie. 200900255

[40] Ting S. S. R., Granville A. M., Quémener D., Davis T. P., Stenzel M. H., Barner-Kowollik C.: RAFT chemistry and huisgen 1,3-dipolar cycloaddition: A route to block copolymers of vinyl acetate and 6-O-methacryloyl mannose? Australian Journal of Chemistry, 60, 49-50 (2007). DOI: $10.1071 / \mathrm{CH} 07089$ 
[41] Schricker S., Palacio M., Thirumamagal B. T. S., Bhushan B.: Synthesis and morphological characterization of block copolymers for improved biomaterials. Ultramicroscopy, 110, 639-649 (2010).

DOI: $10.1016 /$ j.ultramic.2010.02.025

[42] Zhang T., Wu Y., Pan X., Zheng Z., Ding X., Peng Y.: An approach for the surface functionalized gold with $\mathrm{pH}$-responsive polymer by combination of RAFT and click chemistry. European Journal Polymer, 45, 16251633 (2009).

DOI: $10.1016 /$ j.eurpolymj.2009.03.016

[43] Nambiar R., Woody K. B., Ochocki J. D., Brizius G. L., Collard D. M.: Synthetic approaches to regioregular unsymmetrical dialkoxy-substituted poly(1,4-phenylene ethynylene)s. Macromolecules, 42, 43-51 (2009). DOI: $10.1021 / \mathrm{ma} 802215 \mathrm{y}$

[44] Yen Y-C., Ye Y-S., Cheng C-C., Lu C-H., Tsai L-D., Huang J-M., Chang F-C.: The effect of sulfonic acid groups within a polyhedral oligomeric silsesquioxane containing cross-linked proton exchange membrane. Polymer, 51, 84-91 (2010). DOI: $10.1016 /$ j.polymer.2009.11.033

[45] Ballesteros O. G., Maretti L., Sastre R., Scaiano J. C.: Kinetics of cap separation in nitroxide-regulated 'living' free radical polymerization: Application of a novel methodology involving a prefluorescent nitroxide switch. Macromolecules, 34, 6184-6187 (2001). DOI: $10.1021 / \mathrm{ma} 0103831$

[46] Shen X., Kitajyo Y., Duan Q., Narumi A., Kaga H., Kaneko N., Satoh T., Kakuchi T.: Synthesis and photocrosslinking reaction of $N$-allylcarbamoylmethyl cellulose leading to hydrogel. Polymer Bulletin, 56, 137-143 (2006).

DOI: 10.1007/s00289-005-0482-2

[47] Zhuravlev L. T.: Structurally bound water and surface characterization of amorphous silica. Pure and Applied Chemistry, 61, 1969-1976 (1989).

DOI: $10.1351 / \mathrm{pac} 198961111969$

[48] Zhou L., Gao C., Xu W.: Efficient grafting of hyperbranched polyglycerol from hydroxyl-functionalized multiwalled carbon nanotubes by surface-initiated anionic ring-opening polymerization. Macromolecular Chemistry and Physics, 210, 1011-1018 (2009). DOI: $10.1002 /$ macp. 200900134
[49] Chen J., Liu M., Chen C., Gong H., Gao C.: Synthesis and characterization of silica nanoparticles with welldefined thermoresponsive PNIPAM via a combination of RAFT and click chemistry. ACS Applied Materials and Interfaces, 3, 3215-3223 (2011).

DOI: $10.1021 / \mathrm{am} 2007189$

[50] Guo T-Y., Liu P., Zhu J-W., Song M-D., Zhang B-H.: Well-defined lactose-containing polymer grafted onto silica particles. Biomacromolecules, 7, 1196-1202 (2006). DOI: $10.1021 / \mathrm{bm} 051011 \mathrm{t}$

[51] Trenor S. R., Shultz A. R., Love B. J., Long T. E.: Coumarins in polymers: From light harvesting to photocross-linkable tissue scaffolds. Chemical Reviews, 104, 3059-3062 (2004). DOI: $10.1021 / \mathrm{cr} 030037 \mathrm{c}$

[52] Yilgor L., Bilgin S., Isik M., Yilgor E.: Tunable wetting of polymer surfaces. Langmuir, 28, 14808-14814 (2012). DOI: $10.1021 / \mathrm{la} 303180 \mathrm{k}$

[53] Zhang J. L., Srivastava R. S., Misra R. D. K.: Coreshell magnetite nanoparticles surface encapsulated with smart stimuli-responsive polymer: Synthesis, characterization, and LCST of viable drug-targeting delivery system. Langrnuir, 23, 6342-6351 (2007). DOI: $10.1021 / 1 \mathrm{a} 0636199$

[54] Chen M., Dong M., Havelund R., Regina V. R., Meyer R. L., Besenbacher F., Kingshott P.: Thermo-responsive core-sheath electrospun nanofibers from poly $(\mathrm{N}$ isopropylacrylamide)/polycaprolactone blends. Chemistry of Materials, 22, 4214-4221 (2010).

DOI: $10.1021 / \mathrm{cm} 100753 \mathrm{r}$

[55] Rueda J., Zschoche S., Komber H., Schmaljohann D., Voit B.: Synthesis and characterization of thermoresponsive graft copolymers of NIPAAm and 2-alkyl-2oxazolines by the 'grafting from' method. Macromolecules, 38, 7330-7336 (2005).

DOI: $10.1021 / \mathrm{ma} 050570 \mathrm{p}$

[56] Pan S., Kota A. K., Mabry J. M., Tuteja A.: Superomniphobic surfaces for effective chemical shielding. Journal of the American Chemical Society, 135, 578581 (2013).

DOI: $10.1021 / \mathrm{ja} 310517 \mathrm{~s}$

[57] Nishino T., Meguro M., Nakamae K., Matsushita M., Ueda Y.: The lowest surface free energy based on $-\mathrm{CF}_{3}$ alignment. Langmuir, 15, 4321-4324 (1999). DOI: $\underline{10.1021 / 1 a 981727 s}$ 